\title{
A Revolução Cubana na imprensa comunista portuguesa (1959-1964)
}

\author{
João Vítor Mendes Freitas \\ joaovitorsm3@hotmail.com
}

\section{Resumo}

A Revolução Cubana de 1959 teve grande impacto no seio do movimento comunista internacional. Em Portugal, esse movimento manifesta-se na luta clandestina contra a ditadura salazarista. Procura o presente artigo observar e compreender as relações entre Cuba, nos primeiros anos da sua revolução, e o Partido Comunista Português, através da análise do seu meio clandestino de propaganda, o jornal Avante!.

Palavras-chave: clandestino, Cuba, revolução, comunista, imprensa, propaganda.

\begin{abstract}
The Cuban Revolution had a great impact inside the international communist movement. In Portugal, that movement manifested itself through the clandestine fight against the salazarist dictatorship, The present article seeks to observe and comprehend the relations between Cuba, in the first years of the revolution, and the Portuguese Communist Party, through the analysis of it's clandestine vehicle of propaganda, the Avante! Newspaper.
\end{abstract}

Keywords: clandestine, Cuba, revolution, communist, media, propaganda.

\section{Abreviaturas:}

CIA - Central Intelligence Agency.

EUA - Estados Unidos da América

PCC - Partido Comunista Chinês.

PCP - Partido Comunista Português.

PCUS - Partido Comunista da União Soviética.

PSP - Partido Socialista Popular.

URSS - União das Repúblicas Soviéticas Socialistas. 


\title{
Introdução
}

\begin{abstract}
A sua confiança profunda na classe operária e na juventude, sua firmeza de que a grande causa da emancipação social e do comunismo triunfará pela luta dos trabalhadores e dos povos e a sua solidariedade internacionalista, sua convicção inabalável no marxismoleninismo e no internacionalismo proletário, no papel indispensável do Partido Comunista, a sua grande e rica obra como autor, fazem parte da herança de todo o movimento comunista internacional.
\end{abstract}

— Fidel Castro, sobre a morte de Álvaro Cunhal, $2005^{1}$

O movimento de guerrilha liderado pelo Movimento 26 de Julho de Fidel Castro era constituído, inicialmente, por um pequeno grupo de guerrilheiros refugiados na Sierra Maestra, na extremidade oriental da ilha de Cuba. Estes lideraram, durante anos, a luta armada através de uma guerra de guerrilha que, com massivo apoio popular, conquistaria o poder no dia 1 de janeiro de 1959, com a destituição de Fulgencio Batista. Era o início do que seria uma revolução socialista debaixo do nariz dos Estados Unidos, algo que estes dificilmente poderiam tolerar

Acontece que, em Portugal, uma aguerrida oposição ao regime de Salazar (liderada principalmente pelo clandestino Partido Comunista Português) ansiava também por uma revolução. É apenas natural que os comunistas portugueses olhassem com admiração para o sucedido em Cuba. E se as aspirações dos guerrilheiros armados que lutavam nas selvas tropicais cubanas eram, de certo modo, semelhantes às dos comunistas portugueses que operavam na clandestinidade, certamente os seus métodos eram bem diferentes. Enquanto que o Movimento 26 de Julho lutava com balas, o Partido Comunista Português lutava com as palavras. O jornal clandestino Avante! teria um papel de destaque na organização da luta contra o regime fascista do Estado Novo, da mesma maneira que terá um papel de destaque em qualquer investigação sobre a história do Partido Comunista Português, pois será a principal fonte de propaganda do partido e, como tal, a principal fonte de informação sobre as posições do mesmo.

Assim, esta investigação terá o objetivo de analisar as relações do Partido Comunista Português com a Revolução Cubana nos primeiros anos da sua existência, bem como a evolução da sua posição ao longo deste período. Para isto, o Avante! demonstrar-se-á ser a principal fonte de informação. Já que, por questões metodológicas, a precisão cronológica é sempre necessária, o período escolhido vai estar compreendido entre a destituição de Fulgencio Batista, no dia 1 de janeiro de 1959, e a visita de Álvaro Cunhal a Cuba, em Maio de 1964. Reconheço que terminar esta investigação no período da Crise dos Mísseis de 1962 seria uma escolha mais óbvia, já que o episódio representa um claro momento de rutura nas relações internacionais cubanas, no entanto, isso deixaria de fora as repercussões que a Crise dos Mísseis representaria

\footnotetext{
1 “Mensagens de pesar e condolências de personalidades estrangeiras". Avante!, $n^{\circ}$ 1647, 23 de junho de 2005.
} 
nas páginas do jornal clandestino português, e que se iriam estender pelo menos até ao ano de 1964, como iremos ver.

\section{Questões de Investigação}

Para percebermos a natureza das questões que vão ser colocadas nesta investigação, é necessário primeiro perceber a natureza da principal fonte de informação, o jornal clandestino Avante!. Este é um jornal que, pela sua condição de clandestinidade, sofre de duas limitações impossíveis de contornar: a reduzida dimensão das suas edições bem como a regularidade destas, visto que a perseguição sobre os seus autores, tipógrafos e distribuidores por parte da polícia política o limitava a nada mais que uma edição mensal (e, em certos períodos, menos do que isso). Para o contexto desta investigação é importante destacar que o Avante! e as escassas páginas em que consistia a sua publicação tinham como propósito final, para além de manter os seus próprios militantes informados sobre as posições do Partido, lançar a propaganda no seio do operariado português, pelo que a grande maioria dos seus artigos têm como foco as questões nacionais e a oposição ao regime, relatando greves, manifestações, boicotes etc. Como tal, por não servirem um papel tão impactante na máquina de propaganda antisalazarista, os artigos relativos às questões internacionais são mais esporádicos e quase sempre com atenção às movimentações da União Soviética e do bloco socialista (em relação aos quais o partido mantinha uma inevitável intimidade a nível ideológico e político).

Tendo isto em conta, é necessário colocar algumas questões sobre a posição da Revolução Cubana nas páginas do Avante!: Qual é a regularidade da sua invocação, e para que propósito? Em que contextos surge e de que maneira é retratada? Mais importante: irá o Avante! dar mais destaque a Cuba depois da Crise dos mísseis e depois da sua consequente aproximação do bloco soviético?

\section{As inconsistências ideológicas de Fidel Castro nos primeiros anos da revolução}

Antes de partirmos para a análise das menções a Cuba no jornal Avante!, é necessário perceber algumas coisas sobre a natureza e a evolução das intenções do Movimento 26 de Julho.

Aquando da guerra de guerrilha, os militantes do Movimento 26 de Julho muito pouco tinham de comunistas. Aliás, embora certamente radicais, muito pouco tinham de qualquer orientação ideológica. De facto, a única ideologia que vai marcar o movimento de guerrilha cubano de forma consistente durante toda a sua história é o anti-imperialismo, com Fidel Castro e seus companheiros a olharem com indiscutível admiração para os tradicionais libertadores 
latino-americanos, como o venezuelano Simón Bolívar ou o cubano José Martí. A ausência de um programa económico socialista por parte de Fidel Castro iria de resto causar desentendimentos entre o Movimento 26 de Julho e o Partido Socialista Popular, o partido cubano pertencente à III Internacional Comunista. No entanto, não há dúvidas de que nos Estados Unidos a orientação ideológica das guerrilhas cubanas era certamente discutida, e caberia à CIA decidir se se tratava de uma insurreição comunista ou não. Certamente, numa primeira instância, decidiu que não era o caso, já que permitiu a tomada do poder por parte de Fidel Castro sem oposição relevante. ${ }^{2}$

Este provar-se-ia um erro tremendo, já que, mesmo antes do sucesso de Fidel Castro, não faltavam indicadores de que o movimento certamente olhava com desconfiança para os Estados Unidos da América. Poder-se-ia assumir o contrário após uma visita de Fidel Castro a Nova Iorque em abril de 1959, mas o facto é que esta não significou mais do que uma tentativa falhada por parte do governo americano de comprar o apoio de Fidel, com propostas que ele não recusaria, mas que não se mostrou pronto a discutir. ${ }^{3}$ Aliás, o imperialismo dos Estados Unidos em relação à América Latina, aliado às políticas anticomunistas americanas da época, poderia ser suficiente para levar os guerrilheiros anti-imperialistas cubanos a olharem com mais admiração para o marxismo. No entanto, é a polarização política da Guerra Fria que cumpre essa tarefa, já que, se a Revolução Cubana antagonizou os Estados Unidos (nem que fosse ao ameaçar os investimentos americanos em território cubano), certamente esse era também o caminho mais rápido para ganhar o necessário apoio por parte da União Soviética. ${ }^{4}$

E ainda assim há que perceber que embora o socialismo estivesse longe de ser o objetivo consciente de Fidel Castro, este é aplicado em Cuba não apenas devido à consciência ideológica dos guerrilheiros transformados em governantes, mas sim porque a necessidade de agir contra o imperialismo e contra os atrasos sociais e económicos herdados do moribundo regime de Batista exigia a aplicação de medidas socialistas, mesmo que Fidel na altura não as percebesse como tal. Nomeadamente a construção de habitação e escolas, a organização de agregados agrícolas cooperativistas ou geridos estatalmente e o planeamento de um processo de industrialização, especialmente na agricultura. Foi a experiência, e não a doutrina, que fez de Cuba um país socialista. ${ }^{5}$ Afinal, não é por acaso que a CIA, em 1960, se apressou a agir sobre Cuba como se de um país comunista se tratasse, muito antes de Fidel se aperceber sequer que

\footnotetext{
${ }^{2}$ HOBSBAWM, Eric - "The Cuban Revolution and It's Aftermath". In Viva La revolución. Londres: Abacus, 2016. p. 261

${ }^{3}$ BOLINE, Nicholas V. - "Fidel Castro's Grand Strategy in the Cuban Revolution: 1959-1968," Papers \& Publications: Interdisciplinary Journal of Undergraduate Research. Lexington. Vol. 4, 14 (2015).

${ }^{4}$ HOBSBAWM, Eric - The Cuban Revolution and It's Aftermath... p. 262

${ }^{5}$ HOBSBAWM, Eric - “Cuban Prospects”. In Viva La revolución... p.31
} 
a revolução que estava de facto a construir era de cariz socialista, e que, como é lógico, isso não seria tolerado pelos americanos. Não é acaso também que, no mesmo momento em que os EUA se moveram para destruir a Revolução Cubana, a União Soviética se moveu para a defender, com o fornecimento de tanques T-34 que representariam um papel crucial na batalha da Baía dos Porcos. ${ }^{6}$

\subsection{O Partido Socialista Popular e o seu papel no processo revolucionário}

Para perceber as divergências fundamentais entre o Movimento 26 de Julho e o movimento comunista internacional (ao qual pertencia o Partido Comunista Português) nos primeiros anos da revolução é necessário perceber as divergências entre Fidel Castro e o Partido Socialista Popular (PSP), ligado a dito movimento.

A verdade é que o PSP, pelo menos desde a década de 1920, havia desistido da visão romântica de uma insurreição armada em larga escala no território cubano. Aliás, é impossível censurá-lo, já que nem os mais esperançosos dos comunistas poderiam crer na viabilização de uma solução comunista num país localizado a tão pouca distância dos EUA. O primeiro momento de tensão entre Fidel Castro e o PSP surgira ainda antes da formação do movimento de guerrilha e remonta a 1953, quando Fidel organizou um golpe protagonizado por cerca de 100 jovens académicos às fortalezas militares do Oriente. O golpe fracassaria tragicamente e o Partido Socialista Popular apelidaria os seus organizadores de terroristas, reforçando a ideia de que os meios legais seriam o único caminho viável para a conquista de direitos e a melhoria das condições de vida dos trabalhadores. Com a realização do XX Congresso do Partido Comunista da União Soviética, o PSP adotaria rapidamente a linha anti-estalinista de Khrushchev e demonstraria o seu apoio à nova linha de coexistência pacífica proposta pelo mesmo. Este seria o principal ponto de cisão entre o PSP e o Movimento de 26 de Julho. Não obstante, após o desembarque dos cerca de oitenta guerrilheiros cubanos liderados por Fidel Castro na extremidade oriental da ilha cubana, o PSP mudaria a sua posição, reconhecendo a importância da luta de guerrilha, mas apostando numa estratégia alternativa assente na organização de pesadas greves. Este seria, no entanto, o início da colaboração dos dois movimentos, chegando o PSP, já perto do fim da insurreição de Fidel Castro a reavaliar os seus critérios e a colaborar, em alguns momentos pontuais, com a luta de guerrilha, oferecendo apoio à frente liderada por Camilo Cienfuegos e colaborando no sucesso das operações lideradas por Che Guevara. ${ }^{7}$ No

\footnotetext{
${ }^{6}$ ALEKSEEV, Aleksandr Ivanovich - Interview with A. I. (Aleksandr Ivanovich) Alekseev, 1986. [Em Linha] Boston: WGBH Educational Foundation, 1986.

${ }^{7}$ MASSÓN SENA, Caridad - "Los Comunistas Cubanos y Las Luchas Por El Poder Em Los Años 50". Revista de Estudos e Pesquisas sobre as Américas. [Em Linha] Brasília. Vol. 7, nº 2 (2013). p. 249.
} 
entanto, é difícil negar que a sua participação tenha sido mais do que residual, visto que apenas começou quando a guerra estava praticamente ganha.

Apesar disso, e como o próprio Che Guevara escreveria, a cooperação total entre o Partido Socialista Popular e o Movimento 26 de Julho fora impossível devido à incapacidade por parte do primeiro em reconhecer de forma clara o papel da guerrilha e de Fidel na ofensiva revolucionária. A verdade é que os comunistas cubanos tinham uma percepção que se viria a provar irrealista da forma como a luta contra o regime de Batista deveria funcionar, influenciada em grande parte pelos métodos reformistas que dominavam o movimento comunista internacional. E se havia coisa que Fidel Castro percebia é que esses métodos eram incompatíveis com as condições particulares de Cuba. De resto, a desconfiança que o PSP tinha em relação a Fidel provinha também do sectarismo proveniente de anos de isolamento político em relação a outros movimentos de oposição a Batista. É importante também sublinhar que, de igual forma, Fidel Castro nutria um certo (e justificado) nível de desconfiança em relação aos comunistas, devido à aliança política que estes haviam realizado e que ajudara a levar Batista ao poder em 1940. Também o inegável distanciamento por parte do PSP em relação às massas trabalhadoras rurais originou uma cisão entre os dois movimentos. ${ }^{8}$

No entanto, o PSP será o movimento de vanguarda anti-imperialista reconhecido pelo Partido Comunista Português, que, seguindo também a linha soviética, acreditava nos métodos reformistas que haviam condenado os comunistas cubanos ao fracasso. Isso teve, sem dúvida, reflexo no retrato que o PCP pintaria da Revolução Cubana nos primeiros anos da sua existência.

\section{A Revolução Cubana ausente das páginas do Avante! (1959-1961)}

A primeira referência à Revolução Cubana no Avante! ocorre em Abril de 1959, e será a única nesse ano. Surge na quarta página (numa edição com a generosa dimensão de seis páginas, que com certeza é um número acima da média) e ocupa nesta um lugar de destaque, sob o título "CUBA, a luta de todo um povo derrubou o ditador odiado". Esta é uma edição de vital importância no nosso estudo. Nela, o Avante! estabelece uma relação de empatia com a Revolução Cubana e expõe a queda de Fulgencio Batista como um exemplo a seguir pelo povo português, enunciando semelhanças entre o governo do ex-ditador cubano e o regime fascista que governava Portugal. Num período em que a União Soviética ainda pouco ou nada sabia acerca das inclinações de Fidel Castro no contexto da Guerra Fria. ${ }^{9}$ Isto por si só revela um certo nível de independência da propaganda do Partido Comunista Português em relação às

\footnotetext{
${ }^{8}$ MASSÓN SENA, Caridad - “Los Comunistas Cubanos y Las Luchas Por El Poder Em Los Años 50”... p. 252.

${ }^{9}$ HOBSBAWM, Eric - The Cuban Revolution and It's Aftermath... p. 262
} 
políticas da URSS, reconhecendo à Revolução Cubana o papel de destaque na luta antiimperialista. No entanto, e é impossível ignorar a referência que o artigo, já quase no fim, faz ao Partido Socialista Popular, destacando o seu papel "de grande importância" ${ }^{10}$ para o sucesso da Revolução Cubana. Como já vimos antes, isto representa um claro exagero (consciente ou não) da participação comunista nos conflitos de guerrilha, provando que o Partido Comunista Português reconhecia, sim, o valor do movimento de Fidel Castro na libertação do povo cubano, mas não hesitaria em utilizá-lo como propaganda da causa comunista.

Já o ano de 1960 inicia-se com duas referências no Avante! relativas a Cuba, ambas na primeira publicação do ano, na crónica internacional localizada na última página do jornal. Aqui a publicação (que nada mais é que uma revisão dos eventos do ano anterior) destaca a revolução do Movimento 26 de Julho como um dos êxitos que deram início ao ano de 1959, juntamente com o lançamento do satélite Lunik 1 por parte da União Soviética. Em seguida, exalta o caráter anti-imperialista da insurreição e refere a ampla reforma agrária conduzida pelo governo revolucionário, apresentando-a como um exemplo do "alargamento e aprofundamento da luta dos povos coloniais e independentes" e da "luta dos povos da América Latina"". Estas são referências curtas, mas vale destacar que grande parte desta edição de janeiro de 1960 é dedicada à fuga de Álvaro Cunhal da prisão de Peniche, que acontecera na noite de Ano Novo. A própria natureza do Avante! fará com que o jornal ofereça destaque a este tipo de questões, tanto pelo espaço limitado das suas edições como pelo seu objetivo principal de organizar a luta de oposição ao regime em Portugal. Era sua última prioridade (pelo menos até ao alinhamento de Cuba com o bloco socialista) relatar as conquistas de uma revolução recém-nascida no outro lado do oceano.

A próxima referência a Cuba ocorre em Agosto de 1960, no contexto da Conferência Inter-Americana e das queixas do governo cubano na mesma pela organização dos Estados Unidos de "toda a série de conspirações e de provocações contra o governo popular de Fidel Castro" ${ }^{2}$, remetendo para o embargo imposto pelo governo americano a Cuba, suspendendo a compra do açúcar cubano, grande fonte de rendimentos da ilha caribenha. Exalta também o papel da União Soviética e da República Popular da China na supressão desta medida de ataque económico com a compra por parte dos dois países da mercadoria cubana. Faz-se referência também à possível intervenção militar da União Soviética em caso de ataque americano à ilha, o que apesar de demonstrar um maior sentimento de solidariedade por parte do bloco soviético em relação a Cuba, demonstra de forma mais evidente um forte sentimento antiamericano,

\footnotetext{
${ }^{10}$ Cuba, a luta de um povo que derrubou o ditador odiado. “Avante!” série VI. No 274, $1^{\circ}$ Quinzena de Abril de 1959.

${ }^{11}$ Crónica Internacional, o ano de 1959. “Avante!” série VI. № 285, $1^{\circ}$ Quinzena de Janeiro de 1960.

${ }^{12}$ Crónica Internacional. “Avante!” série VI. No 292, Agosto de 1960.
} 
sentimento esse que o Avante! deixa implícito neste artigo, referindo não só a questão cubana, mas também as agressões americanas à república da Venezuela.

Só em Outubro se encontra aquele que é, provavelmente, o artigo de maior destaque e importância neste ano de 1960. Num texto denominado de "TIREM AS MÃOS DE CUBA!"13 o jornal Avante! emite um comunicado de solidariedade com Cuba, denunciando a preparação da invasão militar da Baía dos Porcos que acabará por acontecer no ano seguinte e condenando a utilização da base militar de Guantánamo para o efeito, fazendo uma alusão às bases militares cedidas pelo governo salazarista aos Estados Unidos. Mais do que isso, num discurso claramente anti-imperialista e anticapitalista, denuncia a interferência de várias empresas americanas na preparação da investida militar, com a United Fruit, a Goodyear, a General Electric e a First National Bank, colocando a série de nacionalizações realizadas pelo governo de Fidel Castro como principal causa desta interferência privada. A verdade inegável é que essas nacionalizações foram brutais, estando, no final de 1960, já cerca de $70 \%$ da pequena indústria nas mãos do estado, bem como cerca de $60 \%$ da produção agrícola (com as plantações de açúcar nacionalizadas quase na sua totalidade). Fidel Castro conduziu também a expropriação total (sem indemnizações) das companhias de petróleo, bem como a nacionalização da banca. ${ }^{14}$ Isto não poderia ser tolerado pelo grande capital americano que dominava a economia de Cuba no período pré-revolucionário e, por isso, a Revolução Cubana deveria ser destruída. De facto, se a Revolução Cubana não tinha motivações socialistas (ou, pelo menos, assim pensava Fidel Castro), sem dúvida que tinha motivações anti-imperialistas, e nisso Fidel não estava disposto a ceder um centímetro. Como é lógico, e como já foi referido antes, o antagonismo dos Estados Unidos em relação a Fidel foi suficiente para lhe garantir não só a solidariedade como o apoio soviético, como de resto está bem claro neste artigo do Avante!. Assim, neste mesmo artigo é exaltado o apoio militar da União Soviética em relação a Cuba, chegando a afirmar-se que:

a agressão a Cuba pode significar a guerra mundial. É bom que os imperialistas norteamericanos compreendam que a URSS não abandonará Cuba e que os foguetões soviéticos destruiriam instantaneamente as bases de onde fosse lançada a agressão. ${ }^{15}$

Fica aqui claro que os comunistas portugueses não só sobrestimavam a solidariedade da União Soviética para com Cuba como também os limites que ela estava disposta a ultrapassar em defesa da sua soberania. Quando o ataque realmente chegou, em 1961, constata-se que não foram lançados quaisquer mísseis por parte da URSS.

\footnotetext{
${ }^{13}$ TIREM AS MÃOS DE CUBA! “Avante!” série VI. No 294, Outubro de 1960.

${ }^{14}$ HOBSBAWM, Eric - "Cuban Prospects". In Viva La revolución ... p.29

${ }^{15}$ Idem, XII.
} 
O ano de 1961, apesar de crucial para o desenrolar dos acontecimentos em Cuba, continuou a ter uma cobertura superficial por parte da imprensa comunista portuguesa. $\mathrm{O}$ primeiro artigo direcionado aos eventos do outro lado do atlântico aparece logo em janeiro de 1961, expressando solidariedade com o povo cubano e o governo de Fidel Castro, que por esta altura (e apesar de ainda não se comprometer formalmente com a URSS) já se virava para os soviéticos e o bloco socialista para garantir a segurança da revolução perante a ameaça americana. Enquanto Fidel assegurava o apoio da União Soviética na sua batalha antiimperialista, quase automaticamente assegurava também o apoio do Partido Comunista Português bem como da grande maioria do movimento comunista internacional, levando a redação do Avante! a apelar aos seus leitores neste artigo ao envio de cartas, postais e telefonemas de protesto à embaixada americana em Lisboa. ${ }^{16}$

Em Abril de 1961 ocorre a Invasão da Baía dos Porcos, essencialmente composta por cubanos exilados e armados pelo governo americano, que acaba por falhar. ${ }^{17}$ Logo no mês seguinte o Avante! oferece cobertura ao acontecimento na sua Crónica Internacional intitulada "NOVAS VITÓRIAS DOS POVOS"18. Neste artigo, a redação do jornal clandestino exalta a derrota das forças americanas bem como condena (novamente) a ameaça militar à soberania de Cuba. Lêem-se também palavras sobre o heroísmo de Fidel Castro e das forças militares cubanas face aos invasores, exaltando-se (de forma algo romantizada) o "ímpeto revolucionário do exército cubano dirigido por Fidel Castro". ${ }^{19}$ De qualquer das formas, é certo que este exército, como já vimos, não esteve sozinho na defesa contra os americanos e talvez tenha sido esta ajuda prestada pelos soviéticos que levaria Fidel Castro a ceder nas suas posições ideológicas e formar finalmente, apenas dois meses depois, em Julho de 1961, as Organizações Revolucionárias Integradas, nas quais estava incluído o Partido Socialista Popular, aproximando Cuba cada vez mais do bloco socialista. Afinal, independentemente das divergências entre o Movimento 26 de Julho e o PSP, a força comunista cubana era a única que poderia oferecer a Fidel Castro a capacidade de organização que o seu governo precisava. Como Eric Hobsbawm constata:

A forma de governo de Fidel, suportada por longos monólogos informais, não era forma de dirigir um governo, mesmo que de um país pequeno, ou de dirigir uma revolução por um longo período de tempo. Até o populismo requer organização. O partido comunista era o

\footnotetext{
${ }^{16}$ Contra a agressão americana, solidarizemo-nos com o histórico povo de Cuba. "Avante!" série VI. No 296, janeiro de 1961.

${ }^{17}$ HOBSBAWM, Eric - "Third World and Revolution". In Age of Extremes, the short twentieth century. Londres: Abacus, 1995.

${ }^{18}$ Crónica Internacional: NOVAS VITÓRIAS DOS POVOS, a agressão de Cuba, uma esmagadora derrota dos imperialistas. “Avante!” série VI. No 300, Maio de 1961.

${ }^{19}$ Idem, XVII
} 
único órgão no lado revolucionário que poderia fornecer-lhe precisamente isso. Os dois precisavam um do outro e convergiram. ${ }^{20}$

No entanto, a redação do Avante! estava convicta de que "esta derrota terá grandes repercussões em todo o mundo, e particularmente na luta dos povos da América Latina pela autêntica independência nacional!"21. De facto, a vitória na Baía dos Porcos e a resistência cubana iriam desencadear movimentos de guerrilha por todo o Terceiro Mundo, com especial destaque para a América Latina. O heroísmo da Revolução Cubana tinha tudo para apelar à esquerda do hemisfério ocidental, ansiosa por romantizar a luta guerrilheira das montanhas, mas mais do que isso, tinha tudo para apelar aos críticos de uma União Soviética já descrente na eficiência da revolução armada. Vale salientar que estes movimentos de guerrilha que surgiram no mundo subjugado ao imperialismo americano não apareceram de forma totalmente orgânica, já que o governo cubano de Fidel Castro e especialmente o talentoso líder de guerrilha Che Guevara impulsionaram ativamente e tomaram parte na formação de tais focos de rebelião. ${ }^{22}$

\section{O Avante! e a Cuba aliada do bloco socialista (1962-1963)}

Com a criação das Organizações Revolucionárias Integradas e o alinhamento ideológico do governo de Fidel Castro com o bloco soviético, as menções a Cuba na imprensa comunista portuguesa aumentaram notavelmente. Enquanto até aqui as referências à Revolução Cubana apareciam apenas aquando dos acontecimentos que mais interessavam ao movimento comunista internacional (como a preparação de uma invasão imperialista por parte do maior antagonista da União Soviética), a partir de agora o país é mencionado entre países como o Brasil e a Venezuela, que já há muito ocupavam as páginas do Avante! devido às representações dos seus respetivos partidos comunistas, que estavam presentes em quase todos os artigos referentes à América Latina. Cuba é agora tida pelo jornal clandestino como uma das principais representações do comunismo internacional nas Américas.

A primeira menção a Cuba em 1962 surge na edição de fevereiro, num artigo acerca do Fórum Mundial da Juventude e de uma sessão organizada pelas delegações de Portugal e suas colónias, onde a delegação cubana estava também presente e em que terá, segundo o próprio artigo, "convidado a juventude portuguesa a visitar Cuba". ${ }^{23}$ No número de maio do mesmo ano surge um artigo demonstrando a posição de vários órgãos de esquerda de várias nações face aos presos políticos portugueses. Aqui, no contexto da emissão de um apelo de solidariedade por parte da Junta Patriótica Portuguesa na Venezuela a vários órgãos internacionais, a Rádio

\footnotetext{
${ }^{20}$ Idem, III.

${ }^{21}$ Idem, XVII.

${ }^{22}$ HOBSBAWM, Eric - “The Cuban Revolution and It's Aftermath”. In Viva La revolución... p. 263

${ }^{23}$ Jovens Portugueses no Fórum da Juventude. “Avante!” série VI. No 313, fevereiro de 1962.
} 
Havana é referenciada por também ter difundido este comunicado. ${ }^{24}$ Um artigo de contornos semelhantes aparece também no número de agosto de 1962, no contexto do VIII Festival Mundial da Juventude, ${ }^{25}$ onde a delegação cubana é novamente referida. A questão cubana é abordada mais profundamente, como seria de esperar, na publicação do mês de outubro de 1962, aquando da famigerada Crise dos Mísseis de Cuba. Aqui o Avante! alerta os seus leitores para um possível conflito à escala mundial e defende o papel da União Soviética no apaziguamento das tensões, destacando o contributo constante do bloco socialista para a paz mundial. Deixa um apelo à cooperação dos governos em prol do desarmamento nuclear "sob rigorosa fiscalização". ${ }^{26}$ Certamente uma reação algo exagerada por parte da redação do Avante!, no entanto não menos pertinente para os seus leitores, dadas as circunstâncias de constante medo apocalíptico que marcou os anos da Guerra Fria. Mas ainda assim, se há algo que a Crise dos Mísseis de Cuba acabou por provar é que, para além da defesa dos interesses soviéticos (atendendo à necessidade de uma contrapartida após a instalação de rampas de lançamento na Turquia por parte dos Estados Unidos), o envio de mísseis para a ilha caribenha surge também em defesa da Revolução Cubana e do governo de Fidel Castro, que temia uma nova invasão semelhante àquela de 1961 por parte dos norte-americanos, invasão esta que de facto estava a ser planeada, segundo os documentos desclassificados pelo governo americano nos anos 1990. ${ }^{27}$ Apesar de tudo isto, se a edição de outubro tem uma conotação mais expositiva do que ativista, a edição do mês seguinte é o verdadeiro reflexo da transferência dos ideais da resistência cubana para a realidade europeia. Num artigo intitulado "A provocação contra Cuba. Ativemos a luta em defesa da paz, contra as bases estrangeiras" ${ }^{28}$ exalta-se novamente a "política de paz da União Soviética", mas mais do que isso refere-se à indignação causada pelas provocações americanas à soberania cubana. Pela primeira vez é referida uma manifestação em Portugal cujo principal foco é a solidariedade para com Cuba, condenando-se a supressão policial de uma ação de protesto de "algumas centenas" de operários junto à embaixada americana em Lisboa. Desta forma, conseguimos perceber a dimensão da simpatia com a causa da resistência cubana já neste período através da mobilização das massas operárias portuguesas (num país em que as represálias à manifestação pública, especialmente a pró-comunista, não eram modestas) em manifestações de solidariedade, mesmo que a sua dimensão possa ser exagerada pela própria publicação clandestina. O texto reflete também um sentimento de

\footnotetext{
${ }^{24}$ Solidariedade mundial aos presos políticos portugueses. “Avante!” série VI. № 316, $1^{\text {a }}$ Quinzena de Maio de 1962.

${ }^{25}$ Festival da Juventude. “Avante!” série VI. No 320, Agosto de 1962.

${ }^{26}$ Crónica Internacional: A declaração soviética alerta os povos. "Avante!” série VI. No 322, Outubro de 1962.

${ }^{27}$ CHOMSKY, Aviva. A History of the Cuban Revolution. Chichester: John Wiley and Sons. 2015. p.69

${ }^{28}$ Crónica internacional: A declaração soviética alerta os povos. "Avante!" Série VI. N 322, Outubro de 1962.
} 
empatia face à questão cubana por parte da ação de luta comunista portuguesa: "O nosso povo [...] compreende que a causa da Revolução Cubana é a sua própria causa, é a causa da libertação dos povos. [...]"29 Ainda no mesmo artigo a redação faz uso destes acontecimentos para condenar a cedência de bases militares aos norte-americanos por parte do governo português, uma causa constante na publicação comunista portuguesa e que, logicamente, muito serve aos interesses da União Soviética no contexto da Guerra Fria. Evidencia o fato de que, efetivamente, as bases militares americanas em território português (especialmente aquela localizada na ilha Terceira, Açores) serviam o imperialismo americano no sentido em que auxiliavam os Estados Unidos a manter o controlo do atlântico e consequentemente expandir a sua ação militar em torno da ilha de Cuba. Esta é uma situação evidentemente condenada pelo jornal clandestino e pelo Partido Comunista Português, que em muitos números do Avante! incentiva o operariado português a protestar contra a conivência e o auxílio do governo salazarista face ao imperialismo americano. É evidente a pretensão dos comunistas portugueses de transferirem a causa cubana para a consciência do operariado português. A luta contra o imperialismo e a luta pela construção do socialismo em Cuba seriam a luta contra a ditadura portuguesa de Salazar.

\section{O Avante! e o Partido Comunista Português de mãos dadas com Cuba}

\section{(1963-1964)}

Em 1963, as referências à Crise dos Mísseis do ano anterior começam logo em fevereiro, mas desta vez sob um contexto diferente. Num artigo intitulado "Em defesa da unidade do movimento comunista internacional", o jornal Avante! aborda o tema da cisão do movimento comunista, com a rutura sino-soviética que se evidencia por esta altura mas que já datava de 1960, com o XXI congresso do Partido Comunista da União Soviética. Esta rutura tem um caráter ideológico derivado de um cada vez maior afastamento da União Soviética do pensamento estalinista e da crença na exportação da Revolução de Outubro. Mas esta, por ser uma questão de especial relevância e que se irá refletir, em última instância, na instrumentalização da Revolução Cubana por parte do Avante! em defesa dos interesses e da posição internacional da União Soviética, irá ser abordada com maior detalhe mais abaixo. De momento, o que importa perceber é que o artigo toma uma clara posição pró-soviética e condena o Partido do Trabalho da Albânia (que, no momento da cisão sino-soviética se coloca ao lado do Partido Comunista Chinês em oposição ao que entendiam ser o revisionismo soviético e à política de coexistência pacífica que a URSS tinha vindo a adotar) por se "fechar numa posição

\footnotetext{
${ }^{29}$ A provocação contra Cuba. Activemos a luta em defesa da paz, contra as bases estrangeiras. “Avante!” série VI. $\mathrm{N}^{\mathrm{o}} 323$, Novembro de 1962
} 
dogmática" 30 e pelo desrespeito pelas posições tomadas nas Conferências dos Partidos Comunistas e Operários de 1957 e 1960 . Cuba surge então na argumentação de que a política de coexistência pacífica adotada pela União Soviética de Khrushchev demonstrou a sua superioridade em 1962 contribuindo para acalmar as tensões na Crise dos Mísseis. Esta política de paz é exaltada em contraste com a política imperialista norte-americana noutro artigo do mesmo número do Avante!, em que o nome de Cuba surge como exemplo das muitas políticas de agressão imperialista levadas a cabo pelos Estados Unidos. Novamente a publicação clandestina portuguesa toma a posição do desarmamento nuclear à escala mundial, posição defendida também pela União Soviética que surge no discurso como a principal impulsionadora da humanidade em direção à paz entre os povos, utilizando a Crise dos Mísseis como a prova de que o armamento nuclear é a principal ameaça à estabilidade das relações pacíficas entre o bloco socialista e o bloco ocidental.

Em agosto de 1963 surge nas páginas do Avante! um ataque por parte do Comité Central do Partido Comunista Português à ação do Partido Comunista Chinês durante as tensões de outubro de 1962, tomando novamente o lado da União Soviética. Aqui, o Comité Central acusa os comunistas chineses de adotarem uma posição de passividade face à crise e de elegerem como alvo das suas críticas não o imperialismo americano, mas o Partido de Lenine. ${ }^{31}$ No mês seguinte, em outubro, uma declaração de Álvaro Cunhal aparece quase como sequência do artigo de agosto, em que o mesmo dirige críticas ao Partido Comunista Chinês.

No ano de 1964 as páginas do Avante! vão acalmar as tensões em que no ano anterior tanto haviam envolvido o nome da Revolução Cubana, e só na edição de junho Cuba irá surgir novamente na imprensa comunista portuguesa, noticiando-se a visita que Álvaro Cunhal havia feito à ilha caribenha no contexto das celebrações do $1^{\circ}$ de Maio. Este é um episódio que não pode deixar de ser notado, por ser o que melhor representa as relações de intimidade e solidariedade que os comunistas portugueses desenvolveram com a Revolução Cubana (mesmo que essa relação só tivesse visto progressos reais após o alinhamento de Cuba com o bloco soviético). No artigo é descrita uma entrevista concedida por Álvaro Cunhal ao jornal cubano Hoy, em que o mesmo valoriza o papel da Revolução Cubana na luta antifascista portuguesa, que vê nela um exemplo a seguir e destaca as semelhanças entre a luta do povo cubano e a do movimento comunista português. Valoriza-se também a representação que a luta antifascista portuguesa tem nas publicações cubanas, referindo-se a um certo sentimento de empatia por

\footnotetext{
${ }^{30}$ Em defesa do movimento comunista internacional: uma declaração do Comité Central. "Avante!" série VI. N ${ }^{\circ}$ 326, fevereiro de 1963.

${ }^{31}$ Ainda sobre a crise de Cuba. "Avante!” série VI. No 332, Agosto de 1963.
} 
parte do povo cubano (ou pelo menos, do seu governo) em relação às dificuldades da população portuguesa oprimida pela ditadura salazarista. Esta visita, tal como é demonstrado na edição do mês de julho do mesmo ano, serviu também para colocar em evidência no panorama internacional, especialmente dentro do bloco socialista, a ação levada a cabo pelos comunistas portugueses. Aliás, a visita a Cuba por parte do secretário-geral do partido não foi isolada, seguindo-se quase imediatamente uma visita à Argélia, com contornos semelhantes. ${ }^{32} \mathrm{~A}$ próxima referência a Cuba nas páginas do jornal clandestino português acontecerá no número de setembro num artigo intitulado "A viragem de há 20 anos, o caminho do socialismo" onde os eventos de 1961 e 1962 da história de Cuba são enumerados como um dos focos de guerra mais perigosos desde a Segunda Guerra Mundial. ${ }^{33}$ Por último, em outubro do mesmo ano Cuba é referida duas vezes, a primeira no contexto da preparação de uma Conferência Internacional dos Partidos Comunistas e Operários ${ }^{34} \mathrm{e}$ a segunda numa manifestação de solidariedade quanto à situação de Cuba face ao embargo económico imposto ao país pelos Estados Unidos. ${ }^{35}$

\section{Cuba e a cisão sino-soviética nas páginas do Avante!}

O comunismo chinês nunca pôde ser considerado uma subcategoria do comunismo soviético, da mesma maneira que a China nunca poderia ser considerada uma área de influência soviética. De facto, a cisão sino-soviética, que poria fim às muitas ajudas materiais que a URSS prestava à China, aconteceria em 1960. Foi mais uma das decisões catastróficas que Mao TséTsung tomou entre os anos de 1956 e de 1976, resoluções que, apesar de tudo, eram aceites com relutância pela liderança do PCC, e no caso do "Grande Salto em Frente" com franca oposição, que seria de resto suprimida durante a "Revolução Cultural".

A cisão sino-soviética não pode ser compreendida, portanto, sem entender as peculiaridades do comunismo chinês e as suas divergências fundamentais em relação ao comunismo russo. Ao contrário deste, o comunismo chinês possui ligações escassas com o pensamento clássico do Marxismo. Consiste antes num movimento posterior à Revolução de Outubro cuja principal ligação a Marx é Lenine, ou antes o Marxismo-Leninismo de Estaline que por sua vez leva ao surgimento teórico de um forte "utopianismo chinês" que idealiza uma sociedade de total consenso e de total imersão do indivíduo na coletividade (que Mao TséTsung tenta colocar em prática com a sua Revolução Cultural ${ }^{36}$. Isto entra em colisão com o

\footnotetext{
${ }^{32}$ Cresce a influência do PCP e da oposição, aumentam as dificuldades do regime salazarista. Alarga-se o prestígio do Partido Comunista Português. “Avante!” série VI. N 344. Julho de 1964.

33 A viragem de há 20 anos, o caminho do socialismo. "Avante!" série VI. No 346. Setembro de 1964.

${ }^{34}$ Em defesa da unidade do movimento comunista internacional. Ao Comité Central do P.C.U.S. "Avante!” série VI. No 347. Outubro de 1964.

${ }^{35}$ Crónica Internacional: Viet-Nam, Chipre, Congo e Cuba. “Avante!” série VI. No 347. Outubro de 1964.

${ }^{36}$ HOBSBAWM, Eric - Age of Extremes. Londres: Abacus, 1994. p.467
} 
Marxismo clássico que tem como objetivo final, pelo menos em teoria, a plena realização e autodeterminação do indivíduo. ${ }^{37}$ É inegável que esta divergência ideológica esteve na origem dos problemas que levaram à quebra de relações entre os dois países, especialmente quando Khruschev proferiu, no XX Congresso da União Soviética, um duro discurso sobre Estaline, a sua ação repressiva e o culto da personalidade, num período em que Mao Tsé-Tsung insistia em aplicar medidas económicas na China inspiradas precisamente no legado estalinista, que de resto haveriam de levar ao desastre do "Grande Salto Adiante". ${ }^{38}$ O Partido Comunista Português, como a grande maioria dos partidos comunistas do mundo (à exceção do Partido do Trabalho da Albânia, também comprometido com uma linha Marxista-Leninista ortodoxa de tipo estalinista) iria tomar o lado da União Soviética e subscrever a sua recém-concebida política de coexistência pacífica com o capitalismo do mundo ocidental (embora a narrativa criada fosse de que este era um conceito criado diretamente por Lenine, quando não passava, como os próprios chineses acusavam, de um revisionismo necessário para a sobrevivência do socialismo soviético na conjuntura da Guerra Fria). Assim, a Revolução Cubana, e mais especificamente, a Crise dos Mísseis surge no Avante!, como já foi referido, como um exemplo de que a linha de Khrushchev havia provado ser a mais indicada para manter a estabilidade mundial. ${ }^{39}$ A conclusão lógica desta explanação é que a situação de 1962 em Cuba se tornou num instrumento utilizado pelo PCUS numa frágil tentativa de manter a coesão do movimento comunista internacional (no qual Cuba estava agora indubitavelmente integrada) ao mesmo tempo que se revelou uma ferramenta para o Avante! defender a superioridade da linha de pensamento soviética, temendo que uma divisão do movimento comunista internacional fosse a causa de uma divisão interna no Partido Comunista Português e na sua militância. Era prioritário impedir que isso acontecesse.

\section{Conclusões e considerações finais}

Finalmente, o retrato feito pela imprensa comunista portuguesa à Revolução Cubana sofre, nos seus primeiros anos, algumas mutações notórias. Os propósitos que esta serve na máquina de propagada do PCP variam desde a mais genuína solidariedade com a emancipação de um povo do jugo imperialista até à mais óbvia instrumentalização da sua luta na defesa de posições que vão para além das suas implicações. É inegável que a posição do Avante! sobre a Revolução Cubana e Fidel Castro se altera de forma gradual à medida que a ilha caribenha vai

\footnotetext{
${ }^{37}$ HOBSBAWM, Eric - "End of Socialism". In Age of Extremes, the short twentieth century... p.467

${ }^{38}$ ROBERTS, Priscilla. [et al.] - FORUM: Mao, Khrushchev, and China's Split with the USSR: Perspectives on The Sino-Soviet Split. Journal of Cold War Studies. [Em Linha] Princeton. Vol. 12 (2010).

${ }^{39}$ Em defesa do movimento comunista internacional: uma declaração do Comité Central. “Avante!" série VI. No 326, fevereiro de 1963.
} 
angariando o apoio e a validação da União Soviética, primeiro com o episódio da Baía dos Porcos e posteriormente com a Crise dos Mísseis. Não obstante, a imprensa comunista portuguesa demonstra um certo nível de autonomia face à política soviética ao dirigir-se à Revolução Cubana num período em que esta mal se tinha estabelecido no mapa político internacional. Talvez tenha sido a admiração pelo sucesso dos guerrilheiros cubanos em derrubar um regime político de tendências fascizantes semelhante ao português que tenha causado uma quase imediata aproximação do PCP à revolução de Fidel Castro. Era necessário, antes de mais, reconhecer e aprender com as conquistas do Movimento 26 de Julho (mesmo que manifestamente o PCP não se tivesse mostrado disponível para reconhecer as fragilidades do PSP, seu partido irmão) de modo a trazer para Portugal essa experiência e aqui organizar a oposição ao regime. As causas da emancipação do povo português e cubano tornar-se-iam causas irmãs.

\section{Fontes}

A provocação contra Cuba. Activemos a luta em defesa da paz, contra as bases estrangeiras. “Avante!” série VI. No 323, Novembro de 1962.

A viragem de há 20 anos, o caminho do socialismo. "Avante!" série VI. No 346. Setembro de 1964.

Ainda sobre a crise de Cuba. “Avante!” série VI. N 332, Agosto de 1963.

Contra a agressão americana, solidarizemo-nos com o histórico povo de Cuba. "Avante!" série VI. No 296, janeiro de 1961.

Cresce a influência do PCP e da oposição, aumentam as dificuldades do regime salazarista. Alarga-se o prestígio do Partido Comunista Português. “Avante!” série VI. No 344. Julho de 1964.

Crónica Internacional, o ano de 1959. “Avante!” série VI. № $285,1^{\circ}$ Quinzena de janeiro de 1960.

Crónica Internacional: A declaração soviética alerta os povos. “Avante!” série VI. No 322, Outubro de 1962.

Crónica Internacional: NOVAS VITÓRIAS DOS POVOS, a agressão de Cuba, uma esmagadora derrota dos imperialistas. “Avante!” série VI. № 300, Maio de 1961.

Crónica Internacional: Viet-Nam, Chipre, Congo e Cuba. “Avante!” série VI. No 347. Outubro de 1964

Crónica Internacional. “Avante!” série VI. N² 292, Agosto de 1960. 
Cuba, a luta de um povo que derrubou o ditador odiado. "Avante!" série VI. No 274, $1^{\circ}$ Quinzena de Abril de 1959.

Em defesa da unidade do movimento comunista internacional. Ao Comité Central do P.C.U.S. “Avante!” série VI. No 347. Outubro de 1964.

Em defesa do movimento comunista internacional: uma declaração do Comité Central.

“Avante!” série VI. N 326, fevereiro de 1963.

Em defesa do movimento comunista internacional: uma declaração do Comité Central. “Avante!” série VI. N 326, fevereiro de 1963.

Festival da Juventude. “Avante!” série VI. No 320, Agosto de 1962.

Jovens Portugueses no Fórum da Juventude. “Avante!” série VI. № 313, fevereiro de 1962.

Solidariedade mundial aos presos políticos portugueses. “Avante!” série VI. No $316,1^{\text {a }}$ Quinzena de Maio de 1962.

TIREM AS MÃOS DE CUBA! “Avante!” série VI. Nº 294, Outubro de 1960.

\section{Bibliografia}

ALEKSEEV, Aleksandr Ivanovich - Interview with A. I. (Aleksandr Ivanovich) Alekseev, 1986.

[Em Linha] Boston: WGBH Educational Foundation, 1986. Disponível em WWW: <http://openvault.wgbh.org/catalog/V E6DE72DD9B5A4DCBAB83543D67949E77>.

BOLINE, Nicholas V. - "Fidel Castro's Grand Strategy in the Cuban Revolution: 1959-1968" Papers \& Publications: Interdisciplinary Journal of Undergraduate Research. [Em Linha] Lexington. Vol. 4, n. ${ }^{\circ} 14$ (2015) Disponível em WWW:< https://digitalcommons.northgeorgia.edu/papersandpubs/vol4/iss1/14/>.

CHOMSKY, Aviva. A History of the Cuban Revolution. Chichester: John Wiley and Sons, 2015.

HOBSBAWM, Eric - Age of Extremes, the short twentieth century. Londres: Abacus, 1995.

HOBSBAWM, Eric - Viva La Revolución. Londres: Abacus, 2016.

ROBERTS, Priscilla. [et al.] - FORUM: Mao, Khrushchev, and China's Split with the USSR: Perspectives on The Sino-Soviet Split. Journal of Cold War Studies. [Em Linha] Princeton. Vol. 12 (2010). Disponível em $\quad$ WWW:< https://doi.org/10.1162/jcws.2010.12.1.120>.

MASSÓN SENA, Caridad - "Los Comunistas Cubanos y Las Luchas Por El Poder Em Los Años 50”. Revista de Estudos e Pesquisas sobre as Américas. [Em Linha] Brasília. Vol.7, $\quad \mathrm{n}^{\circ} 2$ (2013). Disponível em https://periodicos.unb.br/index.php/repam/article/view/20229>. 